\title{
Clinical Trial Kick-off Meeting Material
}

National Cancer Institute

\section{Source}

National Cancer Institute. Clinical Trial Kick-off Meeting Material. NCI Thesaurus. Code C115600.

A collection of clinical trial materials for attendees of the initial clinical trial meeting. 